\title{
Muslim Socio-culture and Majority-Minority Relations in recent Sri Lanka
}

\author{
Ahmad Sunawari Long ${ }^{1}$, Dr Zaizul Ab. Rahman ${ }^{1}$, Ahamed Sarjoon Razick ${ }^{2} \&$ Kamarudin Salleh ${ }^{1}$ \\ ${ }^{1}$ Department of Theology and Philosophy, The National University of Malaysia (UKM), Malaysia \\ ${ }^{2}$ Doctoral Candidate, Department of Theology and Philosophy, The National University of Malaysia (UKM), \\ Lecturer, South Eastern University of Sri Lanka \\ Correspondence: Ahamed Sarjoon Razick, Department of Theology and Philosophy, FPI, UKM 43600, Bangi, \\ Selangor Darul Ehsan, Malaysia. Tel: 60-11-1893-1917.
}

Received: August 10, 2016

Accepted: October 8, $2016 \quad$ Online Published: February 28, 2017

doi:10.5539/jpl.v10n2p105

URL: https://doi.org/10.5539/jpl.v10n2p105

\begin{abstract}
Sri Lanka is a nation in which multi-religious, multi-ethnic multi-language people live. Buddhists are the majority, while Muslims form the second minority group next to Tamils. Since historical times, the community relationship between Buddhists and Muslims has been prevailing. However, recently, a disturbing trend has been widely spreading among the Buddhists and Muslims. This situation has emerged during the aftermath of the anti-Muslim campaigns set by a number of Buddhist Nationalist Groups (BNGs), with their main goal being to propagate incorrect opinions about the Muslims to promote negative views about their socio-culture, and to distort the idea of a peaceful relationship between Buddhists and Muslims in the country. Accordingly, in the past several years, they have campaigned against halal certification on consumer goods, hijab and niqab of Muslim women, cattle slaughtering, places of worship and prayer services, among others. Moreover, they spread out the illusion that the above aspects of Muslim socio-culture are notable threats to the Buddhist people. So, these aspects are assumed by the Buddhists to be obstacles for maintaining a community relationship with Muslims. On the above background, analyzing the extent to which the above aspects influence the majority-Buddhists and minority-Muslims relationship, and determining as to whether an unfastened relationship will prevail between them, are the main objectives of this study. Based on the results, it is certainly affirmed that the above Muslim socio-cultural aspects, except slaughtering of cattle, have not pushed their influences to damage the Buddhist-Muslim relationship in Sri Lanka. In this respect, it was found that the aspect of 'slaughtering of cattle' is the only obstacle to the Buddhist-Muslim relationship. Furthermore, the recent campaigns have not changed the Buddhists' mood in terms of maintaining a better relationship with Muslims. Moreover, the campaigns did not change their habits in keeping up the relationships with Muslims, without any break as how they behaved during the war (1984-2009) and pre-war periods. However, it is worthy to note that the BNGs have succeeded through their campaigns to create a negative Muslim stereotype among a small population of Buddhists in Sri Lanka.
\end{abstract}

Keywords: Muslim Socio-culture, majority-minority relations, Buddhists, Sri Lanka

\section{Introduction}

Sri Lanka is a diverse country that is the home of the people of many religions, ethnicities and languages. The Sinhalese are the main ethnic group in the country, constituting three quarters of the total population. Among them, the Sinhala-Buddhists are 70.19\% (Department of Census and Statistics, 2012), and speak Sinhala, an Indo-Aryan language. The Tamils make up the second major ethnic group, constituting $15.37 \%$ of the population. This group consists of Sri Lankan Tamils and Indian Tamils, 12.61\% of whom are Hindus (Department of Census and Statistics, 2012). Tamils live predominantly in the North-Eastern part of the island. The Muslims in Sri Lanka constitute 9.4\% of the country's population (Department of Census and Statistics, 2012), and live in various parts of the country. In some regions, Muslims are more in number compared to Buddhists, and belong to three different ethno-social backgrounds: namely Sri Lankan Moors, Indian Moors and Malays. Others include the Memons and the Bohras (Hussein, 2009). The Muslims are an ethno-religious group, and speak Tamil, a Dravidian language.

The relationship between majority-Buddhists and minority-Muslims have been tightly linked both socially and 
culturally since the early period of the arrival of Muslims to the country. Arab-Muslim traders and local Muslims have immensely contributed to protect and expand their reigns during the regime of Buddhist leaders (Dewaraja, 1994). During the $19^{\text {th }}$ and $20^{\text {th }}$ centuries, Muslim leaders and scholars toiled hard for Sri Lanka's independence from colonial rule. They protected the territorial integrity and sovereignty of the country, irrespective of ethnic, religious and lingual differences. In post-independent era, the relationship between Buddhists and Muslims was strong, and they shared great mutual respect and understanding (Lebbe, 2010). The Muslim group has been identified as a peaceful one that has maintained societal and ethnic harmonious relations with its neighbours. Further, Muslims have also maintained a very good relationship with Buddhist rulers. This cordial relationship with Buddhists and their rulers made the Muslim community in the country among the privileged. In fact, it is worthy to note that, compared to other minorities who are living with majorities in other parts of the world; the Muslims in Sri Lanka have enjoyed a variety of fundamental rights, as well as socio-cultural and economic privileges.

However, recently, in the context of Sri Lanka, especially during the aftermath of the civil war (1983-2009), a series of tense situations have been observed in terms of the relationship between the Buddhist and the Muslim communities. This has started when the Buddhist nationalist groups (BNGs) such as Bodu Bala Sena (BBS), Sinhala Rawaya and Rawana Balaya posed questions about socio-cultural practices and ethnic features of Muslim community. Specially, Muslims' rights pertaining to religious obligations have been immensely questioned through provocations by respective groups. These groups advocated the establishment of a pure Buddhist raj in Sri Lanka. During their rallies, the most prominent hard-liner groups have used coarse, derogatory language to undermine and question Muslims and their religion, and spread misunderstanding and misperception about them among the majority Buddhist community in Sri Lanka. There have been several incidents recorded attacking the Muslim's religious places of worship, which have consequently imposed challenges in practicing religio-cultural identity, customs and fundamentals. In this regard, in the recent past, the Muslims have faced a number of challenges in terms of anti-halal (permitted to eat according to Islam) and anti-hijab (headscarf and face cover) agitations, as well as destroying and damaging places of worship, refusing to call for prayers using loudspeakers, disturbing prayer services, anti-slaughtering movements, anti-Shariah agitations and so on. Furthermore, these groups have propagated and advised Buddhists to reduce or avoid socio-cultural and economic interactions, as well as relations with the Muslim community.

These incidents have created a situation that is suspicious and tense, as well as a feeling of marginalization among the Muslims, especially those live in majorly Buddhist-populated areas throughout the country. Moreover, these incidents have contributed to the clashes in opinions and misunderstandings, thus further damaging the once prevailing healthy relationship between the Buddhists and the Muslims in Sri Lanka. Although Muslims are seen as having remained largely loyal to the state during the 30-year ethnic conflict and civil war, they are currently expressing the fear of religious marginalization, which has increased uncertainty of their co-existence and long-term cordial relationship with other major ethno-religious groups, especially Buddhists. Based on the above backdrop, this study attempts to explore the views of Buddhists on a number of aspects of Muslim socio-culture and to find post-tension majority-minority relations between Buddhists and Muslims in Sri Lanka with a semi structured interview in selected 14 Buddhists majority districts in Sri Lanka.

\section{Materials and Method}

In fact, this study attempts to analyse the views of Buddhists on a few aspects of Muslim socio-culture and find post-campaign community relationship in the current context of Sri Lanka through a semi structured interview with 28 Buddhist participants in selected 14 districts of Sri Lanka as per the selection of two Buddhists from each respective districts. The interviewees were randomly selected as the samples of this research, as done the questionnaires for another research. The researcher directly visited to interviewees' residences with the nominees who already nominated to every selected district by the researcher and met the participants after they were identified and introduced by the respective nominees. It took around 40 minutes time for each interviewee and this was done in the months of November and December 2014. During the interview, a pocket video camera was used with the permission of participants for the purpose of simplifying to transcribe those interviews and to analyse it. So, in this interview the participants were asked to express their opinions and views on a number of Muslim socio-cultural aspects and to what extern the recent campaigns have influenced on community relationship with the Muslims in Sri Lanka.

\section{Results and Discussion}

Under this topic it is described the views of the participants after transcribed and coded manually the interviews collected from them. Further, through this semi structured interview it has investigated the two major items with 
the participants. Item one investigates the Buddhists' view on the aspects of Muslim Socio-culture which are obstacles to the Buddhists propagated by the BNGs. So, this item divided into four major areas that halal, certification, worship places and prayer services, slaughtering of cattle and hijab and niqab of Muslim woman and analysed. Item two tries to investigate the post campaign majority-minority Relations in Sri Lanka. The analysis has started with item 1 below.

\section{Item 1: Controversial aspects of Muslim socio-culture to Buddhists}

In this item the participants requested to identify the aspects of Muslim socio-culture which are seemed to be barriers to make interaction with Muslims during their social life. Specifically the item requests the participants to express their views on the aspects that propagated by the BNGs as threats to Buddhists and Buddhism in this country such as halal certification, mosques and prayer services, slaughtering of cattle, hiajbs and niqabs of Muslim women.

Halal: Consuming halal is a mandatory obligation to the Muslims according to Islam if they live everywhere. So the halal Accreditation Council (HAC) has issued halal certifications since 2007 on consumer products which have a process of becoming finish good with the purpose of monitoring the compliance of international standards of halal compliance within the island, under the observation of the All Ceylon Jamiyyathul Ulama (ACJU) (The national body of Islamic Theologians) (Farook, 2014). But, in February 2013 the BNGs have began campaigns against the halal certifications with propagating that in a majority Buddhist country there did not essence a kind of halal certifications to consumer goods and the Buddhists did not need to adhere the Shariah obligations while they are Buddhists. Also the BNGs have tried to separate the Buddhists from Muslims by making the halal event as an issue (Rifai, 2013). So this item tries to investigate the Buddhist public's opinion that whether or not the halal certification is an obstacle to maintain interaction with Muslims in Sri Lanka.

According to the interview, a group of 30\% participants think about the halal aspect that the country-Sri Lanka is not ruled by the Shariah and the Buddhists as the followers of Buddhism did not need to profess other religious obligations. So it has expressed that the Buddhists could not accept or recognize the halal logo on consumer goods within Sri Lanka. At the same time another participant felt that the goods which printed on halal logo should be sold to Muslims only not to Buddhists, if so in the market it should be available the same goods without halal logo. One participant from Anuradpura says,

"To be frankly I can express here that the halal logo is a big issue for our Buddhists, we as Buddhists we cannot follow other religious obligations. If the Muslims must need halal embedded goods, then, in the market it should be available the same goods which with no halal logo too."

However, at the interview it could be observable that more than $20 \%$ of the Buddhists did not aware of issuance of halal certification on consumer goods, while $50 \%$ of them have accepted and recognized the issuing halal certification in Sri Lanka. One participant from Badulla says,

"The Muslims are how much better than the Buddhists, they always try to consume healthier food, specially the meat, they consume this after slaughtered and ran the blood thoroughly from those animals. So there are no problems issuing halal logo on consumer goods within the country. And also I cannot say this would be an obstacle or barrier of maintain relationship with Muslims."

Also, Ven. Watarka Vijitha Thero has expressed the same opinion as a statement on TV footage during the course of campaigns in 2013. So here it could be observable that most of the Buddhists have been accepted the embedding halal logo on consumer goods and also they did not think this would be a big issue in their daily routine or an interruptive factor of professing their religion-Buddhism. Therefore, it can be expressed that the BNGs dissemination was not been affected so far among most of the Buddhists, especially regarding boycott of halal logo on consumer goods. Also, another thing can be identified that most of the Buddhists did not see the halal aspect as an obstacle of interacting with the Muslims in Sri Lanka.

Worship places and prayer services: As explained earlier, in recent times in Sri Lanka, the BNGs have unleash the protests with the support of Buddhists laity against the Muslim worship places especially located in Buddhists majority areas and against their worships in respective places. And also they have tried to make the Muslim worships and their mosques as an issue to the Buddhists and their religion. According to the interview, the view of most of the Buddhists that they did not look at the mosques and its functions as issues or obstacles to them and they did not feel these mosques interrupt their daily routine matters. A participant from Ratnapura says,

"I say here that I do not face any problem from the Muslims who live in this surrounding, 
even the mosque activities, some time I hear the loudspeaker, also not disturbing us forever, because, they profess their religion, it is just only for few minutes."

This participant feels that the Muslims' prayers are few minutes and he as non-Muslim should allow them to uphold their religious obligations and even he feels that he should be patience if it comes any loud during the course of their worshiping as disturbing them. However, at the interview, it could be observable the frustrations too of some other Buddhists regarding the Muslim worship and their worship places. One participant from Anuradapura district says,

"Sometimes we hear loudspeaker sounds that could be seen as disrupting us or obstacle to our daily operations, but here my opinion is general to every sound we hear. All human beings should profess their religion without disrupting others and also all should have to respect other faiths with abandoning reproaching and condemning it. Also, in my opinion, the problem will be aroused not with the religion, but with construction of the buildings, because some time loudspeakers of mosques disturb the exam candidates during their examination if the exam centres would be located nearby the mosque. And also at night the loudspeakers disrupt the sleeping."

According to the above participant's view, the Muslims are requested by the Buddhists to organize their worships in proper manner as per the guidance of religion. The religion-Islam directs the Muslims to not speak so loudly that can disturb others and keep the voices in between them and others (Al-Qur'an, 31:19). So this obligation is not except to the worships, but the Muslims should adhere to this even during their prayers. Therefore, the Muslims are here expected to understand and pay attention to undertake their prayer activities with no disturbances to the Buddhists, especially they are majoritized areas. It could be observable among the Muslims, especially in month of Ramadan the loudspeakers of most of the mosques put out sounds of the prayers till passing the midnight even in non-Muslim majority areas, even though the loudspeaker is not a Shariah obligation. So the Islam do not welcome the worships with insulting other human beings either Muslims or non-Muslims and it always commands the Muslims towards respecting others' rights everywhere. So here the Buddhists have expressed reasonable complains that the avoidance of the disturbances coming from prayer services. In a previous research the Muslims have accepted that they required proper guidance to maintain prayer services and mosques' functions as not disrupting other faiths within the context of Sri Lanka (Razick, et al., 2016).

Slaughtering of cattle: As mentioned in the introduction, the BNGs have tried to make the matter of slaughtering of cattle which usually carried out by the Muslims in Sri Lanka as an anti-Buddhism activity. So according to the interview, a number of Buddhists did not feel the aforementioned Muslims socio-cultural practices of Muslims as anti- Buddhism activities except slaughtering of cattle (bulls or cows). Hence, the slaughtering of cattle is a disliked practice to the Buddhists by Muslims. However, it could be observable that because of this practice by Muslims the Buddhists did not want to be reduced the interaction between two communities within Sri Lanka. One participant from Kegalle District says,

"There could be observed a few practices of Muslims as anti-Buddhism such as slaughtering of bulls. But, we can understand that this is their culture and at the same time avoiding of animal abuses is our culture, we as Buddhists. So we no need to clash with them, those are their works and let us maintain our works. I am also one, against the slaughtering of cattle, but it is coming under Muslim's culture or religion, whenever they bring meals for me they never add beef with it. So they know I do not eat beef curry and they surely send us meals without beef."

Another one from Puttlam,

"Personally I condemn slaughtering of cattle, but I have known that this is an activity which rewarded by the God according to Muslims' belief."

So both of these participants have tried here to express their understanding with opposite religious faith and they have felt that it is sufficiently enough if they can maintain merely their religious obligations according to Buddha. Also, at the interview, a few Buddhists expressed that Holy Gautama Buddha did not claim elsewhere not to do animal abuses, but He expressed that if human do that he/she will get whatsoever in return. Due to this instruction by Buddha, they feel that it is better for Buddhists to be not to eat beef, if so doing the problem will be solved and no need to compel other religious faiths to stop it and no need to interfere to prevent their religious practices, such as Muslims' Udhhiya (cattle sacrifice) practice in Hajj festive seasons. Also, the Buddhists feel such in this way, because, most of the Buddhists consume beef in Sri Lanka (Jones, 2016) including the particular interviewee in his daily life and they have been benefited with the nutrition of beef consumption. So, a 
particular percentage of Buddhists did not care about slaughtering of cattle and including consuming it. Also those people have considered that if the government gets whatever effort to stop it, then, it is useless attempt within Sri Lanka to stop slaughtering cattle and if do so, the people at least will do hunting and eat beef. So, according to their view stopping of slaughtering of cattle is impracticable within Sri Lanka, because of the people's demand toward it and has been practiced since unknown time in this country.

However, at the interview, most of the Buddhists are strongly condemning the slaughtering bulls or cows within the land and looking at that as an anti-Buddhism activity and a worse interruption in maintaining a better interaction with Muslims. But, they have given concern merely on killing the cattle except consuming its beef. So that they have given permit to import demanded beef from foreign countries to Sri Lanka. A participant from Ratnapura says that,

"The Buddhists nationalist groups (BNGs) sometimes have led the Buddhists with some certain cases related to Buddhism teaching such as cattle slaughtering. So this type of presence by the BNGs, in fact, can be recognizable and cannot be seen wrong, because, this is a predominant Buddhists country, no problem if they import beef to Sri Lanka from foreign countries. So the cattle don't want to be killed, the killing is big sin according to Buddhism, specially, bulls and cows, we never allow to kill them. So, some time because of this practice of Muslims, the community relationships with Muslims might be breakable. If we need to resolve this ongoing unrest which held between Buddhists and Muslims, it should be first stopped the cattle slaughtering within Sri Lanka. This is the first and foremost way to reconcile the conflictual nature."

So the BNGs also claim the same that not to kill cattle within the Buddhist land and they accept that the Buddhists too have been consuming beef within Sri Lanka (Jones 2016). The leading group Bodu Bala Sena too has expressed the same way as its opinion regarding the above issue (Jones 2016). Also Sinhala Rawaya recently has submitted a request to the former president Mahinda Rajapaksha to stop killing cattle within the country (Raisa Wickrematunge, 2013). So at the interview from a sizable Buddhists' view could be observable that they expressed the same argument which requesting the Muslims not to kill and if necessarily they want to eat beef, then, they can import it from foreign countries. So their request is here toward the Muslims that they should adapt to live with a Buddhist surrounding. Moreover, some other Buddhists feel that because of the practice of cattle slaughtering their religion-Buddhism is under disgraceful and it brought the whole Buddhist society toward inferior stage. One participant from Colombo says that, "The practice of slaughtering of cattle is disgusting the whole Buddhist society."

Hijab and Niqab of Muslim woman: As explained earlier, in recent time in Sri Lanka the BNGs have taken effort to spread out a bad image on niqabs and hijabs of Muslim woman among the Buddhist public and to ban the respective dresses within Sri Lanka. In fact, according to the interview of this research, Buddhists did not aware of the hijabs of Muslim women, in contrast, they welcome the hijabs with Abaya (a full-length outer garment worn by Muslim women) which most of the Muslim women wear in public places within the country. A participant from Colombo says that,

"Does not matter, if they wear that dress, it is so good, and they should have tying up with their culture; we don't want to compete with that, it is their wish and they never say us to wear their dress (hijab). Also we cannot say not to wear their attire and cannot compel them to wear like us."

One from Matara expresses,

"One's dress do not cause harm to another one."

So, there are people among the Buddhists welcoming the Muslim women's dress and tolerated on this dress code. Also they did not notice this dress as makes them in disturb.

Also, among the Buddhists there has been a belief that this kind of black coloured full face cover dress is unlucky to them and also a number of Buddhists consider this dress as recently imported from Arab countries to Sri Lanka. One participant from Kegalle District says that,

"Our some Thero instruct us that the black colour dress is not good for our surroundings or environment. This is a worse factor to pollute or affect the surrounding. Actually, this is a dress come from Arab countries, because it is a dress which fits with a dusty environment. But Sri Lanka is not a country like Arab countries. We feel unlucky of this type of dress, means that we look into that as a silly practice of Muslims. If a Muslim woman seen with face 
cover, we always firstly look at the face when we meet that woman, so how can identify a particular woman who is who without looking at the face. However, we cannot say totally to avoid this dress, because, the Muslims wear their dresses according to their religion. So we can recognize it at $80 \%$ out $100 \%$. But the Muslims are not aware of the impacts of this type of dress to others, specially, to the Buddhists."

So, here by the Buddhists, a Muslim woman has not been compelled to not to wear their traditional or cultural dress among the presence of Buddhists, but they have expressed their beliefs according to the Theros' guidance towards the dress code of Muslim woman.

However, there could be seen an incompatible nature of the Buddhists with niqab (face cover) of a Muslim woman. Regarding the niqab, the Buddhists have given concentration on raising consequences caused by it, that they think with the dress- niqab there are so many disadvantages among the society such as theft, robberies and also health problems. Though, the Buddhists have not been forwarded to impress toward Muslims to not to wear it within the country. One participant from Ratnapura says that,

"There are some issues from Muslims side to the Buddhists such as slaughtering of cattle and wearing face cover (niqab) and so on. Actually our kids are afraid of covering full-face of Muslim woman. So here let the Muslims know how to wear timely manner and depend on the place between public. So, specially, the Muslim women's dress code, anyhow, should be organized well as to fit with the surrounding according to their religion, because there is sufficient room to use this dress with robbers and thieves to do their jobs. If it happened so it will not only be an effect to the Muslims, but also a worse massage to other societies as well that this unwise happening has occurred with Muslim women's dress. All the people should understand everything."

Another participant from Kalutara says that,

"Stupid, this is an unwanted practice by a Muslim woman, because, this will harm to the body health if she is wrapped up the whole body with niqab."

So here the Buddhists point out that the Muslim woman's niqab should be organized in proper manner in order to fit with timely and naturedly situations and as not to harm others in public places while their niqab. In a previous research which done by a questionnaire survey, the Muslims have agreed with the above feelings and expectations presented by the Buddhists here (Razick, et.al, 2016). Researcher point of view here is that among the Muslims still prevail various opinions regarding women's niqab as to whether it is compulsory or not according to Shariah. Therefore, first of all this confusion should be removed with an academic investigation in respect of current context in Sri Lanka and then the public will be directed toward the correct path whether wearing or not or wearing in which timely and spatially manner and including maintaining an organized way as not to harm other communities especially.

\section{Item 2: Post-tension Majority-Minority Relations}

Under this item the participants were asked whether or not they have made distance to avoid the interaction with Muslims due to hearing recent misinterpretations about Muslims by the BNGs. At the interview, the researcher observed the sudden answer to this question from Buddhists is 'no', means that it could be understandable that they did not intend to make distance on their community relations with Muslims and they did not aware of misinterpretations propagated by the BNGs. So here it could be noticed the strong understandings among the Buddhists toward Muslims in Sri Lanka. A participant from Colombo says that,

"We have not followed or believed the talks or misinterpretations of BNGs and consequently, we have never tried to decrease or break the relationships with Muslims. Also, we have never allowed talking everything to Bodu Bala Sena General Secretary Gnanasara Thero. We all, Muslims, Buddhists and Hindus should have to live together collectively in a society."

So, according to the above statement there could not be seen room for holding distance between Buddhists and Muslims in terms of community link and at the same time the Buddhists thought always living with peaceful co-existence with other communities with not giving concerns on the BNGs recent campaigns. Also, it could be proved at the interview that Buddhists and Muslims are socially and culturally well interacted communities in Sri Lanka. One participant from Ratnpura says that,

"Actually we have a cordial relationship with the Muslims who live in our surroundings in this village. As soon as hearing sickness to our neighbour, then, we go to see them. Also we participate usually in wedding, funerals and we never face any problems from them. Surely 
we would like that our neighbours are being Muslims. We have thoroughly satisfied the relationship with them. In festival days we distribute the festival foods and they also do same for us. Specially, they give us food during their celebrations with the pattern of ours-Buddhists. So we too do same during our occasions. Also for our social or cultural occasions the Muslims come and help us with taking part in some works. We also do same for their occasions."

So, the Buddhists here do not face any problems by the Muslims who live in their surroundings, and they exchange their thoughts and feelings among them with participating social and cultural events held in their villages. The second participant from Ratnapura says that,

"Even today if it raises any problems to the Muslims, then, we run there immediately to see it and they also do same. When my aunt passed away at the hospital during my absence at home, the Muslim neighbours had gone there before I go there. Specially, in the areas of Eheliyagoda, Ratnapura, Kuruwita the Buddhists and the Muslims are very close and friendly. Really the Muslims are very good people, indeed, among us there is nothing as any problems. We have been participating even at Iftaf programmes (Break fasting event) at the mosques and Meeladu Nabi when they have invited us."

So there could be seen a strong acceptance of minority-Muslims by the majority-Buddhists and occurring a deeper level social assimilation among them even though the Buddhists and the Muslims segregated ethnically and religiously within Sri Lanka. A very good example to this, that the Buddhists have taken part or participated in Muslims religious events in most of the areas of Sri Lanka such as Iftar (Break Fasting Event), Meeladun Nabi (Prophet's Birthday) celebration and so on.

Another thing is observable among them that Buddhists and Muslims jointly have involved in Business as partners and have habits of money lending and borrowing as well. Further, Muslims work under Buddhists bosses and Buddhists work under Muslim bosses. So one from Kegalle expresses that,

"Also we have made the Muslims our business partners within our regular market and we trust them sufficiently in doing business. Our Buddhists work under Muslims as drivers and in some other professions. Some time we lend money to the Muslims, most of the Muslims give it back to us with particular time, but someone does not give it back at promised time, it is not a big matter."

So the Buddhists do not have racism feelings and do not see among them religious differences as well. There is no possibility to raise language based issues, because most of the Muslims in majority Buddhists districts are fluent in Sinhala language which is the predominant Buddhists' language (Nuhaman, 2007). So there could be seen the above situation as an example for existence of economic assimilation among them in the country. Hence, this is a fundamental factor to interact Buddhists with Muslims or vice versa. The following opinion by a participant from Matale has further confirmed the social exchange among their neighbourhood life.

"Indeed, we haven't got racism among us, they visit our homes and we visit their homes. We all should live as siblings of one parent in this country, in my opinion. Whoever either Buddhists or Muslims, they all are human, running same blood in the body. If the human cannot understand this nature, then the universe will be perished."

On the top of this, another important thing could be observable at the interview that the Buddhists have regretted and felt fear of decreasing interaction among Buddhists and Muslims during the aftermath of post-war context. A participant from Kegalle says that,

"In fact, we are observing in this region the trend of withdrawing relationships between Buddhists and Muslims. My husband 30 years ago used to play balls with Muslims, but now we cannot see the same among our kids. However, I am now above 45 years old, compare to early 30 years time, in present days the community relationship among us is gradually decreasing.

So, according to the above statement, in current time, younger generations from both of Buddhist and Muslim societies have not been motivated toward the interaction among them as well as early time. Also, it can be proved that the community relations have been gradually become dim and among youngsters a healthier link has not been replicated nowadays in Sri Lanka. The findings of the research conducted by Herath and Rambukwella' (2015) has argued the same nature of majority-minority relations among societies within the country. Furthermore, the participants urge at their interview not to be held gradual landing of community relations 
among respective societies. A participant from Colombo says that,

"Specially, I afraid of raising this kind of worse context among our children either they are Buddhists or Muslims. Our elder generation has maintained a good collaboration among them and not behaved badly like the BNGs. I think there is enormous possibility to come the relationship down between Buddhists and Muslims at $200 \%$ out of $100 \%$. So this is actually an edge of the relationship hanged on, next step will be the end or full stop. I have a good tightness with Muslims, but my children have not as much as I have. So both sides should behave with mindfully, then, there will not be aroused problems among these societies and let both parties don't want to disturb each other."

The Buddhists express their favours towards the development of an understanding between both of Buddhists and Muslims and towards maintain of good will to respect and regards each other. According to Buddhists, this is the basic way to resolve ongoing issue within the current context of Sri Lanka.

\section{Conclusion}

As a conclusion, this research aims to analyse and find out the influence of some of the Muslim socio-cultural aspects on community relations between the Buddhists and Muslims in Sri Lanka during the aftermath of civil war (2009). For this purpose, 14 administrative districts, where Buddhists reside in majority and Muslims in minority, are selected and from each district two Buddhists were selected for interviewing them as the data of this research. It has identified through the interview that the aftermath of the BNGs' attacks against Muslims and the propagations of misinterpretations about their socio-culture in recent Sri Lanka how the number of aspects of Muslim socio-culture influenced and affected the community relations between Buddhists and Muslims in terms of withdrawing relationships among them. According to the analysis of the interview, the majority of the Buddhists did not satisfy with any sort of conflictual nature among the societies in Sri Lanka. So, it is understood that the efforts of the BNGs undertaken recently has rather failed and not influenced on bring a bad image about Muslim socio-culture among the Buddhists. Though the situation is so, it can be concluded that the misinterpretations or maltreatment of these groups were not followed by most of the Buddhists. However, there are a small portion of Buddhists who have gone forwards in terms of believing of the BNGs and got the Muslims their enemies among the societies. Though these types of people are few, there is possibility for them to be induced by the voicing of the BNGs, and all Buddhists go behind in rallies, seems more in current context of Sri Lanka. So the Government, relevant authorities and other non-governmental organizations are expected again to create condition for prevailing peace against the disturbances and to maintain relationships between Buddhists and Muslims in the country.

\section{References}

Badone Jones, R. N. (2015). Sinhala Buddhist Nationalism and Islamophobia in Contemporary Sri Lanka. Honors Theses, The Faculty of the Department of Anthropology, Bates College.

Department of Census and Statistics-Sri Lanka. (2012). Statistical Abstract of the Democratic Socialist Republic of Sri Lanka. Department of Census and Statistics-Sri Lanka, Colombo, Sri Lanka. Retrieved fromhttp://www.statistics.gov.lk/PopHouSat/CPH2012Visualization/htdocs/index.php?usecase=indicator\&a ction=DSMap\&indId=10\&district=Moneragala\&Legend=3\#

Dewaraja, L. (1994). The Muslims of Sri Lanka One Thousand Years of Ethnic Harmony 900-1915. Colombo: The Lanka Islamic Foundation.

Farook, L. (2014). Muslims of Sri Lanka Under Siege. Colombo: Latheef Farook.

Herath, D., \& Rambukwella, H. (2015). Self, Religion, Identity and Politics- Buddhist and Muslim encounters in Contemporary Sri Lanka. Colombo: International Centre for Ethnic Studies.

Hussein, A. (2009). ZEYLANICA - A Study of the Peoples and Languages of Sri Lanka. Pannipitiya, Colombo: Neptune Publications (Pvt.) Ltd.

Lebbe, L.M.H. (2010). Buddhists' perceptions of Islam and Muslims in Sri Lanka: An empirical study in the context of Da'wah. Unpublished PhD Thesis. Malaysia: International Islamic University Malaysia.

Nuhman, M.A. (2007). Sri Lankan Muslims, Ethnic Identity within Cultural Diversity. International Centre for Ethnic Studies, Colombo.

Raisa, W. (2013, August 4). More Deaths if law isn't changed-Sinhala Ravaya.Retrieved from http://www.thesundayleader.lk/2013/08/04/more-deaths-if-law-isnt-changed-sinhala-ravaya/ 
Razick, A.S., Long, A.S., Ismail, K. Hj., Salleh, K., Saadiah, K., \& Halizah, O. (2016). An Analysis of the Post-War Community Relations betweenBuddhists and Muslims in Sri Lanka: A Muslim's Perspective. Journal of Politics and Law, 9(6), 42-54. https://doi.org/10.5539/jpl.v9n6p42

Rifai, S. (2013, April 17).Patriotism, Allegiance and Loyalty of Sri Lankan Muslims To Mother Lanka, Colombo Telegraph.

Retrieved fromhttps://www.colombotelegraph.com/index.php/patriotism-allegiance-and-loyalty-of-sri-lankanmuslimsto-mother-lanka/

Yehiya, R. (2013). Asymmetric relationship of Buddhist-Muslim bond in Sri Lanka. Retrieved from http://groundviews.org/2013/06/01/the-asymmetric-relationship-of-buddhist-muslim-bond-in-sri-lanka/

\section{Copyrights}

Copyright for this article is retained by the author(s), with first publication rights granted to the journal.

This is an open-access article distributed under the terms and conditions of the Creative Commons Attribution license (http://creativecommons.org/licenses/by/4.0/). 